\title{
EATING HABITS, HYGIENE PRACTICES, PHYSICAL EXERCISES AND SOME ASSOCIATED FACTORS AMONG SCHOOL STUDENTS AGED 13-17 AT HAI PHONG IN 2017
}

\author{
Tran Quynh Anh ${ }^{1,}$, Bui Van Tung ${ }^{1}$, Nguyen Thi Thanh Xuan ${ }^{2}$ \\ ${ }^{1}$ Institute for Preventive Medicine and Public Health, Hanoi Medical University \\ ${ }^{2}$ Department of International Collaboration \& Research, Vietnam National Cancer Hospital
}

A cross-sectional descriptive study with a target to describe eating habits, hygiene practices, physical exercise and some associated factors among school students aged 13-17 at Hai Phong in 2017. A sample of 1548 students participated in the survey using self-reported questionnaires. Results show that most students eating fruits and vegetables $<5$ times/day (75.2\%), and $23.4 \%$ of students drank carbonated soft drinks $\geq 1$ time/day. $43.2 \%$ of students did not usually wash hand before eating and after using the toilet and $34.9 \%$ did not usually wash hand with soap. Most students did physical activity less than 5 days/week (77.9\%); $43.3 \%$ of students did not walk or cycle to school, and $36.4 \%$ did not play sport (during 7 days). Risk factors that increase improper health behavior include students in the age group 16-17, educational attainment of a parent who has not graduated from high school, being overweight/obese and not being educated health. The intervention of school families and society is needed to improve students' health behaviors.

Keywords: GSHS, Students, Health behaviors

\section{INTRODUCTION}

The health-related behaviors of lifestyle during school years have health consequences not only in a younger age but also over the lifecourse, with important implications for public health. A majority of life-threatening disease around the world is associated with health risk behaviors. ${ }^{1}$ Particularly, many of the chronic non-communicable diseases of the adult years are demonstrated to arise from behaviors that start or are reinforced in school years, including unhealthy diets, lack of physical activity, tobacco

Corresponding author: Tran Quynh Anh,

Institute for Preventive Medicine and Public Health,

Hanoi Medical University

Email: tranquynhanh@hmu.edu.vn

Received: 19/02/2021

Accepted: 08/04/2021 smoking, or alcohol consumption. ${ }^{2}$

In 2001, the World Health Organization, in collaboration with the US Centers for Disease Control and Prevention designed the collaborative surveillance project of the Global School-based Student Health Survey (GSHS) to measure and assess the behavioral risk factors and protective factors among students ranging between 13 and 17 years old at the national level. ${ }^{3}$ As of December 2013, 94 countries have participated in the project, and more than 450,000 students have completed GSHS survey. ${ }^{4}$ In Vietnam, a report from the 2013 GSHS showed that the percentage of underweight students was $16.4 \%$, overweight was $6.4 \%$, obese was $1,2 \%$; the proportion of students who usually brushed their teeth less than one time per day, never or rarely washed 
their hands after using the toilet, and first tried an alcohol drink before age 14 years is $2.9 \%$; $58.8 \%$ and $47,2 \%$, respectively. ${ }^{5}$

It is undeniable that health behavior is the critical area where health psychology can and has made significant contributions to improving health among the youth. ${ }^{6}$ Additionally, school students' health behaviors tend to change over time and are influenced by changes in socioeconomic conditions, educational intervention programs. ${ }^{3}$ The immediate and longterm intervention for student health care needs to be based on up-to-date evidence of students' health status in various settings and areas. Although several studies on health behaviors in some provinces within Vietnam were recently implemented, data and information on health risk behaviors in Hai Phong remain limited. Therefore, we did this research with objectives: "To describe eating habits, hygiene practices, physical exercise and some associated factors among school students aged 13 - 17 at Hai Phong in 2017" to provide reference data for future intervention programs.

\section{METHODS}

\section{Research subjects}

Participants who met the following inclusion criteria took part in the survey: (1) was in grade from 7 to 12 in the last school year; (2) agreeing to take part in the study; (3) their parent's agree to let them answer the survey; and (4) having able to read and respond to the questionnaire in Vietnamese.

\section{Method}

Study time: The study was conducted from October 2017 to May 2018.

Study site: The study was conducted in six schools in three districts of Hai Phong province, including three secondary schools and three high schools.
Research design: This research was a cross-sectional study.

Sample size:

$$
\mathrm{n}=\mathrm{Z}_{1-\alpha / 2}^{2} \times \frac{\mathrm{p}(1-\mathrm{p})}{\mathrm{d}^{2}}
$$

- n: Sample size

- $\alpha$ : Level of significance, choose $\alpha=0.05$

- $Z_{1-\alpha / 2}$ : Level of confidence according to the standard normal distribution (for a level of confidence of $95 \%, Z=1.96$ )

- $p$ : Estimated proportion of school students who adopt health behaviors (because this study examines various health risk behaviors, use $p=0.5$ to maximize sample size)

- $d$ : Absolude error (use $d=0,04$ )

By using the formula above, the maximum of students for the survey is 800 . To be more precise, we multiplied it with the design effect $d=2$ Therefore, the sample should be $\times 2=$ 1200 students. We recruited 1548 students in the survey.

Sampling selection: This study employed a multi-stage cluster sample design: (1) At the first stage, purposive sampling selects two schools in the urban area and two in the rural areas. These two schools include one secondary school and one high school. (2) Second, in secondary schools, grades 7,8 , and 9 were chosen, while in high schools, we selected grades 10 and 11. (3) The last stage of sampling consisted of randomly selecting intact classrooms from each grade. We chose two or three classes in each grade depending on the sizes of the classes.

Data collection techniques: The study applied indirect interview techniques with an anonymous questionnaire.

Research tools and measurement methods: This study used a part of the school-based student health survey (GSHS) questionnaire developed by the World Health Organization. The GSHS was first conducted in Vietnam in 
2013 by the Department of Preventive Medicine, Ministry of Health, and concerned authorities with the support of the $\mathrm{WHO}$ and $\mathrm{CDC}{ }^{7}$

This study focused on five key health behaviors among school students. Thus, the survey topics included dietary behavior, hygiene (including teeth cleaning and handwashing), physical activity.

Measure indicators according to $\mathrm{WHO}$ guidelines ${ }^{5}$

Variables: The information was provided/ collected, including (1) Demographic characteristics: gender, age, father's education level, mother's education level, number of siblings, the birth order in the family, academic achievement, conduct, BMI. (2) Student health behavioral characteristics include eating habits, hygiene practices, physical exercises.

\section{Data analysis}

Descriptive statistics were used to examine characteristic data and student health behavior, include frequency and proportion. We applied a binary logistic regression model to determine the factors associated with student health behavior. The significance level was set at $p<$ 0.05 . All statistical analyses were carried out using Stata 15.0 software.

\section{Ethics}

The study proposal was approved by the General Department of Preventive Medicine, Ministry of Health, Vietnam (Decision No96/ QD-DP April 20th, 2017). All students in the study provided their consent before survey was administered. Students were allowed to withdraw from the survey at any time.

\section{RESULTS}

Table 1. Personal characteristics of the participants

\begin{tabular}{llcc}
\hline \multicolumn{2}{c}{ Demographic Factors } & $\mathbf{n}$ & \% \\
\hline \multirow{3}{*}{ Gender } & Male & 746 & 48.2 \\
\cline { 2 - 4 } Age & Female & 802 & 51.8 \\
\hline \multirow{3}{*}{ Father's education level } & $13-15$ & 782 & 50.5 \\
\cline { 2 - 4 } & $16-17$ & 766 & 49.5 \\
\hline \multirow{2}{*}{ Mother's education Level } & Not graduated from high school & 413 & 26.7 \\
\cline { 2 - 4 } & High school graduate or higher & 1135 & 73.3 \\
\hline \multirow{2}{*}{ Number of siblings } & Not graduated from high school & 398 & 25.7 \\
\cline { 2 - 4 } & High school graduate or higher & 1150 & 74.3 \\
\hline \multirow{2}{*}{ The birth order in the family } & Have no siblings & 106 & 6.8 \\
\cline { 2 - 4 } & Have siblings & 1442 & 93.2 \\
\cline { 2 - 4 } & No siblings/firstborn & 782 & 50.5 \\
\cline { 2 - 4 } Academic achievement & Secondborn or younger & 766 & 49.5 \\
\cline { 2 - 4 } & Excellent, Very good & 808 & 52.2 \\
\cline { 2 - 4 } & Good & 638 & 41.2 \\
\cline { 2 - 4 } & Fair & 102 & 6.6 \\
\hline
\end{tabular}




\begin{tabular}{llcc}
\hline & Demographic Factors & $\mathbf{n}$ & \% \\
\hline \multirow{3}{*}{ Conduct } & Very good & 1344 & 86.8 \\
\cline { 2 - 4 } & Good & 167 & 10.8 \\
\hline \multirow{3}{*}{ BMI } & Fair, Weak & 37 & 2.4 \\
\hline & Underweight & 78 & 5.0 \\
\cline { 2 - 4 } & Normal & 1212 & 78.3 \\
\hline
\end{tabular}

The results in table 1 showed that there were 1548 participants, in which the proportion of men and women was equal. Most of the parents' education levels are from high school and above. Almost all subjects have siblings (93.2\%). The ratio of overweight/obese students is $16.7 \%$.

Table 2. Eating habits, hygiene practices, and physical exercises behavior among participants

\begin{tabular}{llc}
\hline \multicolumn{1}{c}{ Behavior } & $\mathbf{n}$ & $\%$ \\
\hline Eating habits & & \\
\hline Eating fruits and vegetable $<5$ times/ day & 1164 & 75,2 \\
\hline Drink carbonated soft drinks $\geq 1$ time/day & 362 & 23.4 \\
\hline Eating fast food $>2$ times/week & 114 & 7.4 \\
\hline Hygiene practices & & \\
\hline Cleaned or brushed their teeth < 2 times/ day & 253 & 16.3 \\
\hline Not usually wash hand before eating and after using the toilet & 669 & 43.2 \\
\hline Not usually wash hand with soap & 541 & 34.9 \\
\hline Physical exercises & & \\
\hline Be physically active for $(\geq 60$ mins/day) < 5 days/week & 1206 & 77.9 \\
\hline Do not walk or cycle to school (during 7 days) & 671 & 43.3 \\
\hline Do not play sport (during 7 days) & 564 & 36.4 \\
\hline
\end{tabular}

Table 2 shows that the majority of study subjects ate fruits and vegetables $<5$ times/day $(75.2 \%)$. A high proportion of students do not usually wash hand before eating and after using the toilet $(43.2 \%)$, not usually wash hand with soap (34.9\%). Most of the study subjects physically active for ( $\geq$ 60 mins/day $)<5$ days/week $(77.9 \%)$. 
Table 3. Some factors associated with eating habits, hygiene practices, and physical exercises behavior among participants

$\begin{array}{cccc}\text { Eating fruits } & \begin{array}{c}\text { Cleaned or } \\ \text { and vegetable } \\ \text { brushed their teeth } \\ <5 \text { times/ day }\end{array} & \begin{array}{c}\text { Not usually } \\ \text { wash hand } \\ \text { before eating } \\ \text { and after using } \\ \text { a toilet }\end{array} & \begin{array}{c}\text { Be physically } \\ \text { active }\end{array} \\ \begin{array}{c}(\geq 60 \mathrm{mins} / \text { day }) \\ <5 \text { days/ week }\end{array} \\ \text { OR }(95 \% \mathrm{Cl})\end{array}$

Gender (vs. Female)

Male $\quad 1.07(0.85-1.35) \quad 1.46(1.11-1.92) \quad 1.19(0.97-1.46) \quad 0.36(0.28-0.46)$

Age (vs. 13 - 15)

$16-17 \quad 1.43(1.14-1.81) \quad 1.05(0.70-0.81) \quad 1.08(0.88-1.32) \quad 1.38(1.09-1.75)$

Mother's education (vs. Completed High school)

$\begin{array}{lllll}\text { Not completed } & 1.68(1.26-2.25) & 1.59(1.19-2.12) & 1.53(1.21-1.92) & 1.10(0.83-1.45) \\ \text { High School } & \end{array}$

Father's education (vs. Completed High school)

Not completed

High School

$1.46(1.11-1.93)$

$1.43(1.07-1.91)$

$1.54(1.23-1.94)$

$1.20(0.91-1.59)$

Birth order (vs. Firstborn)

Middle born or last born

$1.10(0.88-1.39)$

$1.03(0.79-1.35)$

$1.66(1.35-2.04)$

$0.86(0.67-1.10)$

Number of siblings (vs. Not have siblings)

$\begin{array}{lllll}\text { Have siblings } \quad 1.41(0.92-2.16) & 0.78(0.47-1.28) & 0.84(0.57-1.25) & 0.71(0.42-1.19)\end{array}$

Academic achievement (vs. Excellent, very good)

\begin{tabular}{lllll} 
Good & $1.27(0.99-1.62)$ & $1.12(0.85-1.49)$ & $1.40(1.14-1.73)$ & $1.07(0.83-1.37)$ \\
\hline Fair & $1.01(0.63-1.61)$ & $1.43(0.85-2.40)$ & $1.32(0.87-2.00)$ & $0.89(0.54-1.44)$
\end{tabular}

Conduct (vs. Very good)

\begin{tabular}{lcccc}
\hline Good & $1.15(0.78-1.69)$ & $1.35(0.91-2.03)$ & $1.49(1.08-2.06)$ & $0.76(0.52-1.09)$ \\
\hline Fair, Weak & $0.43(0.22-0.83)$ & $1.02(0.42-2.94)$ & $0.93(0.48-1.82)$ & $0.56(0.28-1.13)$
\end{tabular}

Overweight/ Obese (BMI Classification) (vs. No)

$\begin{array}{lllll}\text { Yes } & 1.62(1.22-2.18) & 1.33(0.94-1.87) & 1.11(0.85-1.45) & 1.72(1.27-2.32)\end{array}$

Health education (vs. Yes)

No $\quad 1.11(0.88-1.40) \quad 1.33(0.99-1.79) \quad 1.47(1.19-1.83) \quad 1.55(1.20-2.01)$

The behavior of eating fruits and vegetables the risk factors that increase unhealthy behavior include: age group $16-17(\mathrm{OR}=1.43 ; 95 \% \mathrm{Cl}: 1.14-1.81)$, mother's education not completed high school $(\mathrm{OR}=1.46 ; 95 \% \mathrm{Cl}: 1.68-2.25)$, father education not completed high school $(\mathrm{OR}=1.46$; 
$95 \% \mathrm{Cl}: 1.11-1.93)$, overweight/obese (OR = $1.62 ; 95 \% \mathrm{Cl}: 1.22-2.18)$, next to that protection factors are defined as conduct fair/weak (OR = 0.43; $95 \% \mathrm{Cl}: 0.22$ - 0.83). The behavior hygiene risk factors that increase unhealthy behavior include male $(\mathrm{OR}=1.46 ; 95 \% \mathrm{Cl}: 1.11-1.92$, mother's education not completed high school $(\mathrm{OR}=1.59 ; 95 \% \mathrm{Cl}: 1.19-2.12)$, father education not completed high school $(\mathrm{OR}=1.43 ; 95 \% \mathrm{Cl}$ : 1.07 - 1.91). The behavior washes hand before eating and after using a toilet, risk factors that increase unhealthy behavior include mother's education not completed high school (OR = 1.53; $95 \% \mathrm{Cl}: 1.21$ - 1.92), father education not completed high school $(\mathrm{OR}=1.54 ; 95 \% \mathrm{Cl}$ : $1.23-1.94)$, conduct good $(\mathrm{OR}=1.49 ; 95 \% \mathrm{Cl}$ : 1.08 - 2.06) and not being educated health (OR = 1.47; 95\% Cl: $1.19-1.83)$. The behavior physical exercises, risk factors that increase unhealthy behavior include: age group 16 - 17 (OR = 1.38; 95\%Cl: 1.09 - 1.75), overweight/ obese $(\mathrm{OR}=1.72 ; 95 \% \mathrm{Cl}: 1.27-2.32)$, and not being educated health $(\mathrm{OR}=1.55 ; 95 \% \mathrm{Cl}$ : $1.20-2.01)$.

\section{DISCUSSION}

An adequate intake of fruits and vegetables in the daily diet reduces the risk of heart disease, cancer, diabetes, and obesity. ${ }^{8}$ It is established that unhealthy eating habits that once formed at a younger age can lead to an intermediate and long-term health consequence. ${ }^{9}$ Results from the study show that the great majority of school students (up to $75.2 \%$ ) did not eat the recommended five or more servings of fruits and vegetables on a daily basis. This figure is considerably high compared to that in other developing countries, which, for instance, was $59 \%$ in Thailand. ${ }^{10}$ It might be due to a lack of general awareness and knowledge among students on their health and nutrition as well as the importance of balanced diets. The proportion of students who drank carbonated soft drinks one or more times a day was $23.1 \%$.

On the other hand, the figure for fast food consumption on three or more days during 7 days was slightly $7.4 \%$. This rate is relatively low compared with trends in other countries in the same region. For example, according to the GSHS Thailand report 2015, $56.1 \%$ of the students reported that they had regularly consumed carbonated soft drinks one or more times a day, and $54.7 \%$ of those who had dined at fast-food restaurants on three or more days during 7 days. ${ }^{10}$ One of the main reasons was the fact that two-thirds of the sample located in the rural area where the access or the availability of those products are insufficient to some extent.

Most students pay attention to oral hygiene; our study results showed that only $16.3 \%$ of students brush their teeth less than twice times/ day. This rate is lower than studies in other regions in nine African countries $(22.7 \%)^{11}$, and Myanmar (27.6\%), India (45.2\%). ${ }^{12}$ However, this result is also lower than research in other countries in the region, such as Thailand (12.8\%), Indonesia (11.3\%). ${ }^{12}$ In terms of handwashing behavior, the study found that the proportions reported for not usually wash hand before eating and after using the toilet $43.2 \%$, washing their hands with soap $34.9 \%$. These findings compare somewhat with other regions, i.e., in nine African countries, 37.8\% did not always wash their hands before eating, $41.6 \%$ did not always wash hands after toilet or latrine use, and $65 \%$ did not always wash hands with soap. ${ }^{11}$ As found in previous studies, this study also found that males were at greater risk of sub-optimal tooth brushing than females. ${ }^{11,13}$ Contrary to some other studies, there were no differences in tooth brushing between boys and 
girls, suggesting that gender differences may not be universal and that both boys and girls are at risk of not engaging inadequate personal hygiene behaviors. ${ }^{14,15}$ The study results also showed that the behavior of not usually wash hands before eating and after using the toilet was higher in the group without health education.

Studies have shown that insufficient physical activity would increase the rate of high blood pressure, heart diseases, diabetes, and other NCDs. As a result showed, a substantial majority $(77.9 \%)$ of students in Hai Phong were physically active for a total of at least 60 minutes per day on less than five days during the week preceding the survey. Besides, 43.3\% of the students did not walk or ride a bicycle to or from school. These findings are in line with the results of the Vietnam GSHS 2013 Factsheet, which indicated that students' level of participation in physical activities is low, while the level of sedentary activities is excessively high. ${ }^{5}$ The proportions of physical inactivity obtained in this study are lower than what Aguilar-Farias et al. found in Latin America and the Caribbean ${ }^{16}$ but higher than what was found in Nigeria, ${ }^{17}$ Ghana. ${ }^{18}$ The possible reason for the low level of physical activity among students could explain the strong correlation between sedentary behavior, on the one hand, and the use of computers, televisions, and smartphones. Another reason could be that some students may not have adequate knowledge of physical activity and the health benefits associated with it. Regarding the association factor, the study results showed more inactivity among female students, 16 -17-year-olds, overweight/ obese, and without health education. Other studies done before have also shown similar associations factors. ${ }^{19,20,21}$

This study had several limitations. Firstly, data were self-reported; thus, some respondents might have misreported either intentionally or inadvertently on any of the questions asked. Second, the data were collected in a crosssectional; therefore, we cannot determine causality to any of the study's associated factors.

\section{CONCLUSION}

This study has proved a large number of school students in Hai Phong still did not pay much attention to their health through their performance of health behaviors. Featured as their level of fruits and vegetable intake was relatively low, a substantial majority of students reported engaging in insufficient physical activity, nearly half of our students do not usually wash hands before eating and after using the toilet. Risk factors that increase improper health behavior include students in the age group 1617 , educational attainment of a parent who has not graduated from high school, being overweight / obese and not being educated health. The intervention of school families and society is needed to improve students' health behaviors.

\section{REFERENCES}

1. World Health Organization. 2008-2013 action plan for the global strategy for the prevention and control of noncommunicable diseases: prevent and control cardiovascular diseases, cancers, chronic respiratory diseases and diabetes. 2009. 9241597410.

2. World Health Organization. Health for the world's adolescents: a second chance in the second decade: summary. World Health Organization; 2014.

3. World Health Organization and Centers for Disease Control Prevention. Global schoolbased student health survey. 2013. 
4. Centers for Disease Control and Prevention. Global School-based student Health Survey. https://www.cdc.gov/gshs/pdf/GSHSOVerview. pdf Accessed 23 Feb, 2021.

5. World Health Organization and Centers for Disease Control Prevention. Global Schoolbased Student Health Survey in 2013 - Vietnam Fact Sheet. 2013.

6. Conner M, Norman P. Health behaviour: Current issues and challenges. 2017; 32(8): 895-906.

7. World Health Organization. Global schoolbased student health survey (GSHS) 2013 coreexpanded questions. 2013.

8. Boeing $\mathrm{H}$, Bechthold $\mathrm{A}$, Bub A, et al. Critical review: vegetables and fruit in the prevention of chronic diseases. European journal of nutrition. 2012; 51(6): 637-663.

9. Craigie AM, Lake AA, Kelly SA, Adamson AJ, Mathers JC. Tracking of obesity-related behaviours from childhood to adulthood: A systematic review. Maturitas. 2011; 70(3): 266284.

10. World Health Organization. Thailand 2015 global school-based student health survey. World Health Organization. Country Office for Thailand; 2018.

11. Pengpid S, Peltzer K. Hygiene behaviour and associated factors among inschool adolescents in nine African countries. International journal of behavioral medicine. 2011; 18(2): 150 - 159.

12. Peltzer K, Pengpid S. Oral and hand hygiene behaviour and risk factors among in-school adolescents in four Southeast Asian countries. International journal of environmental research and public health. 2014; 11(3): 2780-2792.

13. Tran D, Phongsavan P, Bauman AE, Havea D, Galea G. Hygiene behaviour of adolescents in the Pacific: associations with socio-demographic, health behaviour and school environment. Asia-
Pacific journal of public health. 2006; 18(2): 3-11.

14. Ranasinghe S, Ramesh S, Jacobsen $\mathrm{KH}$. Hygiene and mental health among middle school students in India and 11 other countries. Journal of Infection and Public Health. 2016; 9(4): 429-435.

15. Rani MA, Sathiyasekaran B. Personal hygienic practices of school going adolescentsacross cectional study in Chennai. Indian journal of community health. 2013; 25(2): 197-199.

16. Aguilar FN, Martino FP, Carcamo OJ, et al. A regional vision of physical activity, sedentary behaviour and physical education in adolescents from Latin America and the Caribbean: results from 26 countries. International journal of epidemiology. 2018; 47(3): 976-986

17. Oyeyemi AL, Ishaku CM, Oyekola J, et al. Patterns and Associated Factors of Physical Activity among Adolescents in Nigeria. PloS One. 2016; 11(2):e0150142.

18. Guthold R, Stevens GA, Riley LM, Bull FC. Global trends in insufficient physical activity among adolescents: a pooled analysis of 298 populationbased surveys with 1.6 million participants. The Lancet Child \& adolescent health. 2020; 4(1): 23-35.

19. Tremblay MS, LeBlanc AG, Kho ME, et al. Systematic review of sedentary behaviour and health indicators in school-aged children and youth. The international journal of behavioral nutrition and physical activity. 2011; 8: 98.

20. Trang NH, Hong TK, Dibley MJ, Sibbritt DW. Factors associated with physical inactivity in adolescents in Ho Chi Minh City, Vietnam. Medicine and science in sports and exercise. 2009; 41(7): 1374-1383.

21. Peltzer K, Pengpid S. Leisure Time Physical Inactivity and Sedentary Behaviour and Lifestyle Correlates among Students Aged 1315 in the Association of Southeast Asian Nations Member States, 2007-2013. International journal of environmental research and public health. 2016; 13(2): 217. 